\title{
Advances in technology research of chemical approach to marine oil spill
}

\author{
Yunzhe $\mathrm{Ji}^{\mathrm{a}}$, Haomeng $\mathrm{Xu}^{\mathrm{b}}$ and Xiaojie Wang ${ }^{\mathrm{c}}$ \\ Service College, Naval University of Engineering, Tianjin 300450, China

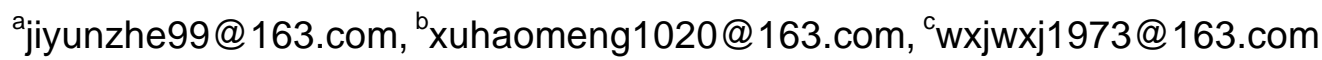

\begin{abstract}
Keywords: marine oil spill, processing technology, chemical method
Abstract. With the deepening of marine oil development and the rapid development of marine oil transport and oil industry, marine oil spills become common, causing serious environmental pollution and economic losses. Therefore, for the sudden oil spill incidents, the rapid and effective measures are able to reduce pollution damage and harm to a minimum, which is very necessary. At present, domestic and foreign marine oil spill treatment technology mainly consists of physical methods, chemical methods, and biological methods. This paper focuses on chemical treatment of marine oil spill accidents, summarizing in terms of the principle characteristics, adaptable environment, influence factors, in order to provide guidance and reference for marine oil spill.
\end{abstract}

\section{Preface}

According to media reports, nearly 30 years, there are nearly thousands of times oil spill accidents happened on China's coastal waters ships and marine drilling platforms, up to about 35,000 tons of oil spill. Oil spill occurs frequently, not only causing significant economic losses, but bringing more harm to the natural environment and human health. At present, the oil content in China coastal waters has exceeded the standard 2-8 times; therefore, we are facing great risk of marine oil spill disaster. Fast and efficient method for collecting and processing the oil slick at sea, clearing the sea oil spill, has great significance in the natural world and human survival and sustainable development of society.

Currently, marine oil spill treatment methods can be divided into three types according to their nature, physical methods, chemical methods and biological methods. Among them, the chemical method is simple and convenient, economical and practical, largely makes up for lack of mechanical recycling, and has played an important role in many large oil spill incident. Chemical oil spill treatment is divided into combustion method and chemical agent treatment as below:

\section{Combustion Method}

Combustion method is to add incendiary agent in oil slick for ignition until the oil is burned completely. Oil spill combustion technology is an effective way to deal with large amount of oil spill in short period.

This method has been applied oil spill in the US Mexico Gulf and oil spill in Dalian. Combustion need to understand the characteristics of the oil spill, and the heat reaching the ignition point is required. If the oil is thick enough to block, after continuous heating, oil block will burn. If the oil film is thin, the ongoing water keeps cooling, combustion will be obstructed. In order to maintain oil block burning, avoid excessive heat dissipation underwater, and oil block thickness should reach $2 \sim 3 \mathrm{~mm}$, for weathered oil, it should reach $3 \sim 5 \mathrm{~mm}$, for residual oil, it should reach $5 \sim 10 \mathrm{~mm}$. Allen [1] and others came through the test conditions for the application of combustion technology: wind speed does not exceed $37 \mathrm{~km} / \mathrm{h}$, sea conditions are not more than three degrade, the flow rate against the oil boom does not exceed $0.75 \mathrm{kn}$, and the water content in oil spill is no more than $25 \%$. In addition, emulsified oil spill will have an adverse effect on the burning; the burning should be in the shortest possible time after the spill. Therefore, in the event of an oil spill, promptly surround oil spill by fencing for burning is particularly important.

Site burning of oil spill has low cost, high clearance rate (up to $95 \%$ or even higher if the oil film is properly controlled), less time-consuming, and without regard to storage, transportation and recycling 
of oil and water mixture processing, so it is an effective means of cleaning a lot of oil spill in a short time. While burning oil spill treatment has its own advantages, but this method is not only to burn valuable energy, and likely to cause air pollution and thermal pollution, incomplete oil combustion will release smoke, including a large number of aromatic hydrocarbons, they also pollute the oceans and the atmosphere, and are more dangerous in the port area and coastal, so the method should be used for oil spill treatment off the coast of the sea water.

\section{Chemical Agent Treatment Method}

Chemical agent treatment method is a method to change the existing form of oil spills in sea water with a chemical agent, make the oil condensing into an oil block in order to let the mechanical device recover it or emulsify it into the sea for naturally elimination. This method is used for the harsh weather conditions and sea state for large oil spill cleanup. Chemical agent treatment includes emulsifying agent, gelling agent and collector agent.

Emulsifying and Dispersing Agent. Emulsifying and dispersing agent, also known as a dispersing agent, is a mixture of surfactant and a solvent contributing to penetration, is the most widely used chemical treatment, being suitable for $0.05 \mathrm{~cm}$ or less oil film thickness; the dispersant can decompose surface oil slick and make it up and down underwater. When the dispersant is evenly sprayed in the sea mixed with the oil spill, surfactant molecules are arranged on the oil-water interface, reducing the surface tension of the oil-water interface, making the oil film being dispersed into small droplets in a few microns and being easy to mix with the sea thoroughly in favor of seawater chemical degradation and biodegradation occurs, so as to achieve the purpose of degreasing. Advantages of emulsification process of oil spill are: removing oil from the surface of the water, so that the film cannot be re-formed, and thus oil would not adhere to ships, reef and marine structures; for the emergency, the mechanical recycling is not allowed to use or there is fire hazard, timely spraying dispersants can reduce hydrocarbon diffusion, reducing the risk of explosion and fire, providing a time guarantee for further measures to; add dispersants in open water is far more economical than mechanically remove when the oil goes into the coastline. The disadvantage of this method is: the use of dispersing agent can cause secondary pollution of the marine ecological environment, although the toxicity of the third generation of dispersant is low, the shadow of its harm to marine life are always lingering.

Dispersant efficiency of oil spill is affected by many factors, including oil viscosity, pour point, and degree of weathering, film thickness and salinity, temperature and the like. In addition the use of dispersants is limited by time and place, in dealing with the oil spill, must grab the opportunity to put the dispersant, strive to complete within two hours after the spill occurred. For the presence of other waters in coastal or harbor, water exchange is not ideal, the storm is not big enough and there are other issues affecting the the role of a dispersant. At the same time the use of dispersants is expensive, combined with dispersant application operating is complex, the operator must be skilled, untrained personnel is difficult to do the job. The advantage of the dispersant oil spill treatment is that it's suitable for offshore and open water with better exchange conditions are relatively good environment, is the first choice under harsh conditions, but some surfactants are toxic to microorganisms, because the oil is dispersed, expanding environmental impact and bringing negative biological effects. In addition, the dispersed oil may also re-coalesce and float to the surface. Therefore, the EPA states: Except in the event of fire and emergency situations, dispersants are not allowed to use. China's relevant laws and regulations strictly limit the use of chemical dispersants. Currently, it is only an auxiliary method of handling oil spills.

Gelling agent. Gelling agent could coagulate oil into viscous oil until to the block, or absorb oil to form substance easily be recovered. By casting gelling agent around oil film, compress the film, so the film area greatly reduced, the thickness increased, which are cemented viscous or hard jelly-like, and then be recovered. The operational principle of gelling agent is different depending on variety, such as sorbitol tyrosol derivatives gelling agent collects oil first and then form into gel, it's effective to thin oil with low toxicity; the natural vinegar gelling agent could form oil-in-water emulsion on high viscosity 
after spraying the oil film, can be mechanically removed. In recent years, the gelling agents reported by foreign reports include polypropylene glycol ethers and polyoxyethylene alkyl ether and leather fiber. In China, until the late 1990s, oil spill gelling agent were listed in national research projects, at present, Li Zhongyi [2] in Dalian University of Technology has developed the amino acid type gelling agent, Tang Shikun[3] in Sun Yat-sen University has developed sorbitol type gelling agent, Chen Guohua and others in Qingdao Ocean University have synthesized polyvinyl alcohol type, soy protein and starch series gelling agent [4,5]. Hunan Shaoyang Chemical Technology Development Institute [6] developed a gelling agent YG-02 after several years of painstaking research. The product enables making oil spill into block rapidly, floating on the water, and be easy to recover, which has significant advantages: make different types of oil (crude oil, heavy oil, light oil, etc.) and some oily materials (benzene, toluene, etc.) into coagulation; can handle oil-in-water emulsion; make internal oil condensation in the on-rock ships and sinking ship; unaffected from the storms; non-toxic, does not produce secondary pollution; the effect is significant, a part of product should condense 3-4 parts of crude oil. But these gelling agents still have some distance from the practical application. The advantage of using gelling agent is low toxicity, recyclable oil spill, little impact from the storm flow, can effectively prevent the oil spreading, with the use of booms and recovery, the efficiency of oil spills treatment is improved.

Collector agent. Collector agent is a surfactant of preventing the spread of oil, being equivalent of chemical booms, suitable for use in harbor, sea areas, and as adjunct means before laying out booms. The principle is it contains surface active ingredient which can greatly reduce the surface energy of the water, change the water, oil, air phase interfacial tension balance, drive film thickening, so as to control the spread of oil film. Gelling agent is to make oil spill become gelatinous coagulation and collector agent make the spread oil gathered but not to make it gelled. Since the collector agent collects the thin oil and then restrain the diffusion, and with the thickness increases, its effect is reduced, and therefore after using collector agent, timely adopt mechanical methods to collect. Polyacrylamide series, acrylamide series, polyvinyl series and early resorcinol, lignosulfonates are currently the main foreign products, with good effect. Current domestic QS series collector agents [7] are made of N, N- dialkyl amine and surfactant preparation. In addition, Chen Guohua in Qingdao Ocean University, many other research institutions and teams have been studied the application of carboxylic acid [8]. The disadvantage of this method is collector agent has less effective in wind speed $>2 \mathrm{~m} / \mathrm{s}$ situation. Usually it will be difficult for the open sea, and effect is poor for more than $50 \%$ of the oil -in- water emulsion blocks, especially for clayey oil, when there are more than $50 \%$ of water, it will not play any aggregation roles.

\section{Conclusions}

The chemical agents for oil spill treatment generally gather and thicken or coagulate oil spill to change the form of its presence in the marine environment, thereby reducing oil spill pollution in seawater. However, the use of chemical agents will bring some negative factors, some chemicals themselves may cause pollution in the marine environment, and so chemical agents must be used in accordance with the relevant provisions, to avoid secondary pollution to the environment. The combustion process is the last method when the other measures cannot effectively deal with the situation.

\section{References}

[1] A.A. Allen and R.j. Ferek. Proceedings of the 1993 International Oil Spill Conference (1993), p. 765-772.

[2] Zhongyi Li. Journal of Dalian University of Technology. 36(1996), p. 120-122. (In Chinese)

[3] Shikun Tang and Zhihong Chen. Environmental Protection in Transportation. 16(1996), p. 17-18. (In Chinese) 
[4] Yunming Sun, Huilan Liu, Guohua Chen and Jinming Song. Marine Sciences. 25(2001), p. 37-41. (In Chinese)

[5] Yunming Sun, Jinming Song and Guohua Chen. Marine Environmental Science. 20(2001), p. 9-12. (In Chinese)

[6] Zhigang yao. Oil and Gas Storage and Transportation. 1996, p. 38. (In Chinese)

[7] Shizhen Li, Zhengtian Hou. Ocean Technology. 14(1995), p. 105-114. (In Chinese)

[8] Guohua Chen, Hongshen Wang, Tao Lou. Acta Petrolei Sinica(Petroleum Processing Section). 22(2006), p. 81-86. (In Chinese) 